\title{
G6. RISK ASSESSMENT: PROSPECTIVE APPROACH ON INTEGRITY INSPECTION LINE OF AN ORAL VACCINE'S PRIMARY PACKAGE.
}

André Vinícius Costa Ribeiro ${ }^{1}$; Miguel Angel de la O Herrera ${ }^{1}$; Elezer Monte Blanco Lemes ${ }^{1}$.

${ }^{1}$ Bio-Manguinhos.

INTRODUCTION Good Manufacturing Practices (GMP) establish the norms, procedures and obligations, which must be met by companies and manufacturers of biological supplies. Their main goal is the risk reduction associated to manufacturing. The processes validation is based on the documented evidence, in which a system performs pre-established processes, following normative specifications and attributes of quality, reducing loss, with less incidences of deviation, creating solid bases for the programs of risk assessment.

OBJECTIVE This paper proposes through a case study the risk assessment in a process of integrity inspection line of an oral vaccine's primary package, reaching consistent data for elaboration of a prospective validation.

METHODOLOGY This study was conducted to perform the risk evaluation in an oral vaccine's primary package inspection process in two stages. The first stage evaluated risks of two equipments comprising the line of inspection using the HAZOP tool to identify the operability of the equipment risks, and to propose actions to minimize potential risks. The second stage used the FMEA tool to identify failure modes and the respective causes and effects of the environmental conditions in process areas, resulting in action proposals and mitigation measurements.

RESULTS Through the HAZOP approach it was possible to identify 39 deviations in both equipments for inspection of integrity. Risks were classified as $28.21 \%$ acceptable; $53.85 \%$ non-acceptable; $2.56 \%$ critical and $15.38 \%$ unacceptable. FMEA's analysis listed 22 failure modes associated to thegeneration and maintenance of environmental conditionssystem, being $22.73 \%$ classified as tolerable and $77.27 \%$ as negligible. 
CONCLUSION The risk evaluation by the HAZOP and FMEA analysis allowed the prospective identification of the associated risks to the inspection process of package integrity of an oral vaccine, assuring improvement actions and other measures to risk mitigation. A new evaluation might be necessary in the future, when the inspection line will be in operation.

KEYWORDS risk assessment, FMEA, HAZOP, integrity inspection. 